\title{
Detection of Cytotoxic Necrotizing Factor Types 1 and 2 among Fecal Escherichia coli Isolates from Brazilian Children with and without Diarrhea
}

\author{
Ana Terezinha Tavechio, Lilian Regina M Marques/+ ${ }^{+}$Cecília Mari Abe*, Tânia AT Gomes*
}

Seção de Bacteriologia, Instituto Adolfo Lutz, Av. Dr. Arnaldo 355, $9^{\circ}$ andar, 01246-902 São Paulo, SP, Brasil *Departamento de Microbiologia, Imunologia e Parasitologia, Escola Paulista de Medicina, Unifesp, São Paulo, SP, Brasil

The enteropathogenic role of cytotoxic necrotizing factor (CNF)-producing Escherichia coli was investigated by searching cnf genes among 2074 isolates from 200 children with and 200 without acute diarrhea in Brazil. Fourteen $(7 \%)$ cases versus $10(5 \%)$ control children carried at least one $\mathrm{cnf}$ positive isolate $(\mathrm{P}=0.50)$ and most isolates expressed CNF type 1. DNA sequences of virulence factors of extraintestinal pathogenic E. coli (ExPEC) were detected in 78.6\% of CNF1-producing isolates. Besides not being associated with human acute diarrhea, the CNF1-producing isolates here identified may represent potential ExPEC transitorily composing the normal intestinal flora.

Key words: Escherichia coli - cytotoxins - cytotoxic necrotizing factor - adhesins

Cytotoxic necrotizing factor (CNF), a toxin firstly detected in extracts of Escherichia coli isolates from children with acute diarrhea in Italy, induces the progressive formation of multinucleated cells in certain cultured lines (CHO, Vero, HeLa, HEp-2), necrosis in the rabbit skin and in the mouse footpad, and death of mice inoculated by the intraperitoneal route. Two types of CNF have been identified (CNF1 and CNF2) and the cell activities of these toxins are due to their ability to constitutively modify the Rho proteins, a family of small GTPases that regulate the physiology of cell cytoskeleton (De Rycke et al. 1999).

The single structural gene encoding prototype CNF1 (cnfl) is located on a chromosomal pathogenicity island, which has also the codifying genes for $\alpha$-hemolysin $(h l y)$ and P-fimbriae or pyelonephritis-associated pilus ( $p a p$ ), whereas the $c n f 2$ gene is located on a high-molecular weight plasmid (De Rycke et al. 1999). CNF1 is frequently produced by extraintestinal pathogenic E. coli (ExPEC) isolated from humans with urinary tract infection (De Rycke et al. 1999, Russo \& Johnson 2000, Boquet 2001) and occasionally detected in isolates from feces of children with diarrhea (Elliot et al. 1998, Okeke et al. 2000, Paciorek 2002). Production of CNF2 has been mainly found among isolates from calves with diarrhea or septicemia (Orden et al. 1999, De Rycke et al. 1999, Van Bost et al. 2001a).

Financial support: Fundação de Amparo à Pesquisa do Estado de São Paulo, grant 90/2450-0

${ }^{+}$Corresponding author. Fax: +55-11-3085-3505.E-mail: lmarques@ial.sp.gov.br

Received 21 July 2003

Accepted 16 January 2004
The role of CNF-producing E. coli strains in diarrheal diseases has not been defined. Recently, Van Bost et al. (2001b) reported that CNF2-producing strains were able to colonize the intestines, cause long-lasting diarrhea, and invade the blood stream of newborn colostrum-restricted calves after experimental inoculation through the oral route. A previous report on the experimental infection of germfree colostrum-deprived newborn piglets showed no evidence for a pathogenic role of CNF1 in the development of diarrhea (Fournout et al. 2000). To date, there is no report on a comprehensively case-control epidemiological study of the association of CNF-producing $E$. coli strains with human diarrheal diseases. Therefore, such association was investigated by searching sequences homologous to the cnf genes among isolates from feces of children with and without acute diarrhea in the largest city of Brazil (São Paulo City). The characterization of all cnf-positive isolates identified with regard to the presence of established or putative virulence factors commonly detected in ExPEC is also reported.

A total of 2074 E. coli isolates from 200 children (1-4 years old) with bloody or non-bloody acute diarrhea (1030 isolates) and 200 age-matched non-diarrheic children (1044 isolates) was studied. E. coli strain J96 was included as the control for cnfl, hly, and pap genes (Blum et al. 1995). Strains S5 (Pérès et al. 1997), KS52 (Labigne-Roussel et al. 1985), and K-12 HB101 (pANN801-13) (Ott et al. 1986) were the controls for $c n f 2$, afimbrial adhesin ( $a f a)$, and $\mathrm{S}$ fimbrial adhesin $(s f a)$ genes, respectively. E. coli laboratory strains HB101 and C600 were used as negative controls. All isolates and strains were stored in $15 \%$ glycerol at minus $70^{\circ} \mathrm{C}$.

Bacterial colony blots were prepared and hybridized under stringent conditions with labeled DNA probes as previously described (Maas 1983). The $c n f$ and hly probes used were the 335 bp PstI-ClaI fragment of pEOSW1 
(Oswald et al. 1994) and the $\sim 6 \mathrm{~Kb}$ AvaI-A fragment of pSF4000 (Welch et al. 1983), respectively. Probes for pap, sfa, and $a f a$ consisted of amplified products $(328,410$, and $750 \mathrm{bp}$, respectively) generated by PCR from prototype strains as previously described (Le Bouguenec et al. 1992). For detection and characterization of cytotoxic activity, all cnf probe positive isolates were submitted to citotoxicity and neutralization assays with rabbit antiserum specific for CNF (types 1 and 2) in HeLa cells as previously described (Marques et al. 2003). Statistical analysis was performed with the Epi Info version 5.01b software (Dean et al. 1991) and a $P$ value less than 0.05 was considered to show a significant difference.

Among the 2074 E. coli isolates, 73 (3.6\%) harbored cnf sequences (43 isolates from children with diarrhea and 30 isolates from children without diarrhea). The frequency of detection of at least one cnf positive isolate among the 200 case children and the 200 controls were 14 $(7 \%)$ and $10(5 \%)$, respectively $(P=0.50)$. Culture supernatants from all cnf positive isolates induced multinucleation of HeLa cells. The CNF1 anti-serum neutralized the activity expressed by 70 isolates ( 65 complete and 5 partial neutralizations), whereas the anti-CNF2 neutralized the activity of 3 isolates ( 2 complete and 1 partial neutralization). Among the CNF1-producing isolates, 55 (75.3\%) hybridized with the pap probe and all harbored hly and sfa sequences, but none had afa homologous sequences. As shown in the Table, 3 different genetic profiles were found among the cnf positive isolates and the most frequent profile was cnf, hly, pap, sfa. None of the CNF2-producing isolates harbored DNA markers other than cnf. Seventeen out of the 24 children with CNF-producing isolates had more than one isolate studied and all isolates showed the same genetic profile.

Ten CNF1-producing E. coli isolates had been previously characterized as carriers of DNA sequences and/or producers of one type of cytolethal distending toxin (Marques et al. 2003) and expression of this toxin accounted for the partial neutralization of toxic activity by anti-CNF1 obtained with the preparations from 5 isolates. Production of another type of cytolethal distending toxin

\section{TABLE}

Genetic profiles and type of cytotoxin produced by 73 fecal Escherichia coli isolates with DNA sequences of cytotoxic necrotizing factor

\begin{tabular}{lcc}
\hline Genetic profiles $a$ & $\begin{array}{c}\text { Number of } \\
\text { isolates }(\%)\end{array}$ & $\begin{array}{c}\text { Type of } \\
\text { cytotoxin }\end{array}$ \\
\hline cnf, hly, pap, sfa & $55(75.3)$ & CNF1 ${ }^{c}$ \\
cnf, hly, sfa & $15(20.6)$ & CNF1 \\
cnf & $3(4.1)$ & CNF2 \\
\hline
\end{tabular}

$a$ : cnf, cytotoxic necrotizing factor gene; $h l y$, alpha-hemolysin genes; pap, pyelonephritis-associated pilus genes; $s f a$, S fimbrial adhesin genes; $b$ : determined by neutralization of cytotoxic activity by specific antisera to CNF1 or CNF2; $c$ : ten isolates carried DNA sequences of cytolethal distending toxin and expression of this toxin was detected in five isolates by neutralization of cytotoxic activity with specific antiserum. may also account for the partial neutralization obtained for one CNF2-producing isolate since Pérès et al. (1997) found DNA sequences of both CNF2 and cytolethal distending toxin in the same plasmid of some $E$. coli strains.

The lack of association between CNF-producing $E$. coli strains and acute diarrhea in the population studied was corroborated by the finding of established enteropathogenic agents in the feces of $11(79 \%)$ children with diarrhea (data not shown). The characterization of the fecal CNF1-producing isolates indicated that all might be regarded as potential ExPEC composing, at least transitorily, the normal intestinal flora.

\section{ACKNOWLEDGEMENTS}

To Dr J De Rycke and Dr E Oswald (Nouzilly, France) for kindly supplying the CNF1 and CNF2 control strains, antisera, and probes.

\section{REFERENCES}

Blum G, Falbo V, Caprioli A, Hacker J 1995. Gene clusters encoding the cytotoxic necrotizing factor type 1, Prs-fimbriae and $\alpha$-hemolysin form the pathogenicity island II of the uropathogenic Escherichia coli strain J96. FEMS Microbiol Letters 126: 189-196.

Boquet P 2001. The cytotoxic necrotizing factor 1 (CNF1) from Escherichia coli. Toxicon 39: 1673-1680.

De Rycke J, Milon A, Oswald E 1999. Necrotoxic Escherichia coli (NTEC): two emerging categories of human and animal pathogens. Vet Res 30: 221-233.

Dean AG, Dean JA, Burton AH, Dicker RC 1991. Epi Info: a general-purpose microcomputer program for public health information systems. Am J Prev Med 7: 178-182.

Elliott SJ, Srinivas S, Albert MJ, Alam K, Robins-Browne RM, Gunzburg ST, Mee BJ, Chang BJ 1998. Characterization of the roles of hemolysin and other toxins in enteropathy caused by alpha-hemolytic Escherichia coli linked to human diarrhea. Infect Immun 66: 2040-2051.

Fournout S, Dozois CM, Odin M, Desautels C, Pérès S, Hérault F, Daigle F, Segafredo C, Laffitte J, Oswald E, Fairbrother JM, Oswald IP 2000. Lack of a role of cytotoxic necrotizing factor 1 toxin from Escherichia coli in bacterial pathogenicity and host cytokine response in infected germfree piglets. Infect Immun 68: 839-847.

Labigne-Roussel A, Schmidt MA, Walz W, Falkow S 1985. Genetic organization of the afimbrial adhesin operon and nucleotide sequence from a uropathogenic Escherichia coli gene encoding an afimbrial adhesin. J Bacteriol 162: 12851292.

Le Bouguénec C, Archambaud M, Labigne A 1992. Rapid and specific detection of the pap, afa, and sfa adhesin-encoding operons in uropathogenic Escherichia coli strains by polymerase chain reaction. J Clin Microbiol 30: 1189-1193.

Maas R 1983. An improved colony hybridization method with significantly increased sensitivity for detection of single genes. Plasmid 10: 296-298.

Marques LRM, Tavechio AT, Abe CM, Gomes TAT 2003. Search for cytolethal distending toxin production among fecal Escherichia coli isolates from Brazilian children with diarrhea and without diarrhea. J Clin Microbiol 41: 22062208.

Okeke IN, Lamikanra A, Steinrück H, Kaper JB 2000. Characterization of Escherichia coli strains from cases of childhood diarrhea in Provincial Southwestern Nigeria. J Clin Microbiol 38: 7-12.

Orden JA, Ruiz-Santa-Quiterai JÁ, Cid D, García S, De La 
Fuente R 1999. Prevalence and characteristics of necrotoxigenic Escherichia coli (NTEC) strains isolated from diarrhoeic diary calves. Vet Microbiol 66: 265-273.

Oswald E, Pohl P, Jacquemin E, Lintermans P, Van Muylem K, O'Brien AD, Mainil J 1994. Specific DNA probes to detect Escherichia coli strains producing cytotoxic necrotising factor type 1 or type 2. J Med Microbiol 40: 428-434.

Ott M, Hacker J, Schmoll T, Jarchau, T, Korhonen TK, Goebel W 1986. Analysis of the genetic determinants coding for the S-fimbrial adhesin (sfa) in different Escherichia coli strains causing meningitis or urinary tract infections. Infect Immun 54: 646-653.

Paciorek J 2002. Virulence properties of Escherichia coli faecal strains isolated in Poland from healthy children and strains belonging to serogroups O18, O26, O44, O86, O126 and O127 isolated from children with diarrhoea. J Med Microbiol 51: $548-556$

Pérès SY, Marchès O, Daigle F, Nougayrède JP, Hérault F, Tasca
C, De Rycke J, Oswald E 1997. A new cytolethal distending toxin (CDT) from Escherichia coli producing CNF2 blocks HeLa cell division in G2/M phase. Mol Microbiol 24: 1095-1107.

Russo TA, Johnson JR 2000. Proposal for a new inclusive designation for extraintestinal pathogenic isolates of Escherichia coli: ExPEC. J Clin Microbiol 181: 1753-1754.

Van Bost S, Bâbe MH, Jacquemin E, Mainil J 2001a. Characteristics of necrotoxigenic Escherichia coli isolated from septicemic and diarrheic calves between 1958 and 1970. Vet Microbiol 82: 311-320.

Van Bost S, Roels S, Mainil J 2001b. Necrotoxigenic Escherichia coli type- 2 invade and cause diarrhoea during experimental infection in colostrum-restricted newborn calves. Vet Microbiol 81: 315-329.

Welch RA, Hull R, Falkow S 1983. Molecular cloning and physical characterization of a chromosomal hemolysin from Escherichia coli. Infect Immun 42: 178-186. 